\title{
Glucose infusion response on some metabolic parameters in dairy cows during transition period
}

\author{
Enrico Fiore', Matteo Gianesella', Francesca Arfuso², Elisabetta Giudice², Giuseppe \\ Piccione ${ }^{2}$, Marcello Lora' ${ }^{1}$ Annalisa Stefani ${ }^{3}$ and Massimo Morgante ${ }^{1}$ \\ 'Department of Animal Medicine, Productions and Health (MAPS), University of Padua, Legnaro, Italy, ${ }^{2}$ Department of \\ Veterinary Sciences, University of Messina, Polo Universitario dell'Annunziata, Messina, Italy, ${ }^{3}$ Istituto Zooprofilattico \\ Sperimentale delle Venezie, Legnaro, Italy
}

\begin{abstract}
The aim of this study was to evaluate the effect of glucose tolerance test (GTT) on glucose, insulin, non-esterified fatty acids (NEFA) and $\beta$-Hydroxybutyrate (BHB) concentration in dairy cows during prepartum and postpartum period. Forty Two clinically healthy Holstein cows were enrolled in two high producing dairy farms in the Northeast Italy. All animals were divided into two equal groups on the basis of the farm of origin: Group A (farm located in Vicenza) and Group B (farm located in Padua). Body condition score (BCS) was determined for both groups. GTT was performed $7 \pm 5$ days before and $7 \pm 5$ days after calving. Blood samples were collected from each animal before (TO) and after the administration of glucose at different times. Plasma concentration of glucose, insulin, NEFA and BHB was evaluated. Application of two way analysis of variance (ANOVA) showed no significant effect of farm and a significant effect of transition period (prepartum and postpartum) on BCS for both groups. Multivariate analysis of variance (MANOVA) was applied to determine significant effects of infusion glucose time, transition period and farm on glucose, insulin, NEFA and BHB. No significant difference was observed between Groups $A$ and $B$ and a significant effect of transition period and glucose infusion was found on all parameters studied. Results confirm that glucose is an important direct controller of metabolic response in dairy cows during the transition period because of the inappropriate energetic supply that characterizing this physiological phases.
\end{abstract}

Keywords: dairy cows, glucose tolerance test, prepartum and postpartum period, haematochemical parameters

Archiv Tierzucht 57 (2014) 3, 1-9

doi: 10.7482/0003-9438-57-003

Corresponding author:

Giuseppe Piccione; email: gpiccione@unime.it

Department of Veterinary Sciences. Polo Universitario Annunziata, University of Messina. 98168, Messina, Italy

2014 by the authors, licensee Leibniz Institute for Farm Animal Biology (FBN), Dummerstorf, Germany

This is an Open Access article distributed under the terms and conditions of the Creative Commons Attribution 3.0 License (http://creativecommons.org/licenses/by/3.0/).

Received: 8 October 2013

Accepted: 14 January 2014 Online: 11 March 2014 
Abbreviations: ADF: acid detergent fibre, AUC: area under curve, ANOVA: analysis of variance, BCS: body condition score, BHB: ß-Hydroxybutyrate, GTT: glucose tolerance test, MANOVA: multivariate analysis of variance, NDF: neutral detergent fibre, NEB: negative energy balance, NEFA: non-esterified fatty acids, NFC: non fibre carbohydrates

\section{Introduction}

The transition period was defined as the change from a gestational non-lactating to a nongestational lactating state (Morgante et al. 2012). It is characterized by changes in both metabolic and immune functions in animals (Piccione et al. 2012). Some of these alterations are related to increases in energy requirements driven by both fetal needs and lactogenesis. During this period, dairy cows showed a marked decrease in dry matter intake that is related to physical, behavioral, metabolic and hormonal changes around parturition (Grummer et al. 2004, Allen et al. 2005). As a result, dairy cows enter a negative energy balance (NEB) that is further aggravated by the nutrient prioritization towards the mammary gland (Leroy et al. 2008). The NEB status is characterized by alterations in blood metabolite and hormone profile (Piccione et al. 2012). Glucose metabolism takes on increased significance in the ruminants during pregnancy (Aldoretta \& Hay 1999, Morgante et al. 2012). Increased glucose requirements of the gravid uterus during late pregnancy and even greater requirements of the lactating mammary glands necessitate major adjustments in glucose production and utilization in maternal liver, adipose tissue, skeletal muscle, and other tissues. During late pregnancy and early lactation hepatic glucose synthesis is increased to accommodate uterine or mammary demands even if the supply of dietary substrate is inadequate and glucose utilization by adipose tissue and muscle is reduced and glucose up-take by adipose tissue and muscle is reduced. Glucose demands during early lactation was greater than during the period of late pregnancy (Contreras \& Sardillo 2011). These responses, exaggerated by moderate undernutrition status in pregnant animals, are mediated by reduced tissue sensitivity and responsiveness to insulin, associated with decreased tissue expression of the insulin-responsive facilitative glucose transporter (GLUT4) (Bell \& Bauman 1997). Peripheral tissue responses to insulin remain severely attenuated during early lactation but recover as the animal progresses through mid-lactation (Guesnet et al. 1991, Bell \& Bauman 1997, Sasaki 2002). Thus, during the period of NEB, key hormone expression and tissue responsiveness alter to increase lipolysis and decrease lipogenesis, causing high levels of non-esterified fatty acids (NEFA) and $\beta$-hydroxybutyrate (BHB) concentration which are indicative of lipid mobilization and fatty acid oxidation (Sakha et al. 2006, Wathes et al. 2009). Excessive fat mobilization can induce an imbalance in hepatic carbohydrate and fat metabolism, which may result in ketosis (Herdt \& Emery 1992, Goff \& Horst 1997). Ketosis is a metabolic disorder that primarily occurs 2-7 weeks after calving (Gillund et al. 2001) and is associated with increased concentrations of NEFA and decreased levels of glucose in blood (Itoh et al. 1998, Nielsen \& Ingvartsen 2004). The ketone bodies, acetoacetate (AcAc) and acetone (Ac) can be reduced to BHB in an enzymatic reaction or decarboxylated to Ac in a spontaneous nonenzymatic reaction (Nielsen \& Ingvartsen 2004). Ketosis causes economic losses to the dairy farmer due to treatment costs, decreased milk production, impaired reproduction efficiency and increased involuntary culling (Nielsen \& Ingvartsen 2004). 
The evaluation of NEFA and BHB represents a strategy for the monitoring of subclinical ketosis and prepartum negative energy balance in dairy cows (Contreras et al. 2010). The intravenous Glucose tolerance test (GTT) was useful to studying the physiological adaptation of animals to transition period since it produced a specific insulin response path (Morgante et al. 2012).

The aim of this study was to evaluate the effective modifications of some metabolic parameters (glucose, insulin, NEFA and BHB) in Holstein cows during transition period after Glucose Tolerance Test.

\section{Material and methods}

\section{Farm condition and animals}

42 multiparous Holstein cows were selected from two high producing dairy farms in the Northeast Italy. The data were collected from October 2011 to February 2012.

The cows were divided into two equal groups on the basis of the farm of origin: Group A, represented by cows obtained from farm located in Vicenza, Italy $\left(45^{\circ} 33^{\prime} \mathrm{N} ; 11^{\circ} 34^{\prime} \mathrm{E} ; 39 \mathrm{~m}\right.$ above sea level) and Group B, represented by cows obtained from farm located in Padua $\left(45^{\circ} 24^{\prime} \mathrm{N} ; 11^{\circ} 52^{\prime} \mathrm{E}, 12 \mathrm{~m}\right.$ above sea level). Both farms make a dry period of 60 days and a period of steaming-up of 15 days before calving. Farms were selected with the same milk production (about $10000 \mathrm{~kg}$ for year); moreover milk yield quality was not different: both farms had an average of 3.7 of milk-fat \%, and the same values (3.4) of milk protein \%. All the animals were clinically healthy and free from internal and external parasites. Their health status was evaluated based on rectal temperature, heart rate, respiratory profile, appetite, fecal consistency, and hematologic profile. Each animal was kept under natural photoperiod and ambient temperature. Body condition score (BCS, 0 to 5 scale) was evaluated before the start of trial in each subject. Table 1 shows the chemical composition of diets used during steaming-up and subsequent early lactation. The value of NDF (neutral detergent fiber), ADF (acid detergent fiber), NFC (non fiber carbohydrates), starch and crude protein, are the same in both farm. Water was available ad libitum.

Table 1

Chemical composition of diets used during steaming-up and subsequent early lactation in both farms

\begin{tabular}{lcccc}
\hline \multirow{2}{*}{ Chemical composition, \% } & \multicolumn{2}{c}{ Group A } & \multicolumn{2}{c}{ Group B } \\
& Steaming-up & Early lactation & Steaming-up & Early lactation \\
\hline Crude protein & 12.63 & 16.59 & 12.87 & 16.66 \\
Ethreal extract & 4.18 & 6.01 & 4.55 & 5.32 \\
Ash & 7.55 & 7.42 & 7.83 & 7.34 \\
NDF & 43.25 & 33.17 & 43.99 & 33.41 \\
NFC & 33.39 & 38.81 & 33.56 & 38.27 \\
Dry matter degradable & 58.58 & 68.48 & 59.68 & 68.22 \\
ADF & 24.66 & 20.37 & 24.46 & 20.12 \\
Starch & 16.71 & 25.46 & 16.49 & 25.94 \\
\hline
\end{tabular}




\section{Blood sampling and analysis}

Glucose tolerance test was carried out $7 \pm 5$ days before and $7 \pm 5$ days after calving. All animals were received sterile $50 \%$ glucose solution at a dosage of $0.25 \mathrm{~g} / \mathrm{kg}$ body weight. Polyethylene catheters were aseptically inserted into both external jugular veins (one for the injection and the second for blood sampling) one the day prior to the experiment. Blood samples were collected into vacuum tubes (BD Vacutainer Systems, Preanalytical Solutions, Plymouth, UK) containing lithium-heparin. Blood samples were taken at T0 (preadministration), and at $\mathrm{T} 2, \mathrm{~T} 5, \mathrm{~T} 10, \mathrm{~T} 15, \mathrm{~T} 20, \mathrm{~T} 30, \mathrm{~T} 40, \mathrm{~T} 60, \mathrm{~T} 80, \mathrm{~T} 100, \mathrm{~T} 120, \mathrm{~T} 140, \mathrm{~T} 160(2,5$, $10,15,20,30,40,60,80,100,120,140,160$ minutes post-glucose administration). Samples were refrigerated and they were processed in the laboratory for analyses. The tubes were centrifuged (Labfuge 400, Heraeus) at $1750 \mathrm{~g}$ for $10 \mathrm{~min}$ and the obtained plasma were stored at $-18^{\circ} \mathrm{C}$ one hour after blood collection. All samples have been tested for glucose with a Cobas C 501 analyser (Roche Diagnostics, Mannheim, Germany). On Cobas C 501 were performed also NEFA and BHB analysis: NEFA concentrations were determined by using a colorimetric method, NEFA RX Monza test (kit no. FA 115, Randox, Crumlin, UK) while BHB concentrations were determined by RANBUT RX Monza test (kit no. RB 1007, Randox, Crumlin, UK). Free-insulin concentration in each sample was quantified with a commercial 125I-IRMA kit developed for human samples (BI-Ins IRMA kit; CIS Bio International Ltd.) and previously validated for bovine plasma samples (Kerestes et al. 2009).

\section{Statistical analysis}

Two way analysis of variance (ANOVA) was applied to determine significant effect of different period (prepartum and postpartum) and farm on BCS. Multivariate analysis of variance (MANOVA) was applied to determine significant effects of infusion glucose time, transition period (prepartum and postpartum) and farm effect on glucose, insulin, BHB and NEFA. $P$-value $<0.05$ was considered statistically significant. Bonferroni's multiple comparisons test was used for post hoc comparisons. Area under curve (AUC) of total glucose, insulin, NEFA and $\mathrm{BHB}$ in the prepartum and postpartum period were calculated.

All statistical analyses were performed using Statistica 7.0 (StatSoft Inc., Tulsa, OK, USA). All the results were expressed as Mean Values \pm Standard Deviation ( $M \pm S D$ ).

\section{Results}

The results showed no significant effect of farm $(P=0.32)$ and a significant effect of transition period $(P<0.05)$ on $\mathrm{BCS}$.

Higher BCS values in prepartum period respect to postpartum period were found in both Groups (Figure 1).

Statistical effect of glucose infusion and transition period on glucose, insulin, BHB and NEFA was found $(P<0.001)$, while no statistical effect of farm was found $(P>0.05)$ (Figure 2).

Table 2 shows mean values of AUC \pm standard deviation of total glucose, insulin, NEFA and $\mathrm{BHB}$ in the prepartum and postpartum period. 
Table 2

Mean values of AUC \pm standard deviation of total glucose, insulin, NEFA and BHB in the prepartum and postpartum period

\begin{tabular}{lcc}
\hline Metabolic parameters & Prepartum period & Postpartum period \\
\hline Glucose AUC, mmol/l & $795.74 \pm 76.68$ & $752.06 \pm 80.22$ \\
Insulin AUC, pmol/l & $26412.46 \pm 2532.21$ & $13973.52 \pm 1381.47$ \\
NEFA AUC, $\mathrm{mEq} / \mathrm{l}$ & $30.99 \pm 2.79$ & $102.47 \pm 8.63$ \\
BHB AUC, $\mathrm{mmol} / \mathrm{l}$ & $82.71 \pm 9.31$ & $109.54 \pm 11.57$ \\
\hline
\end{tabular}

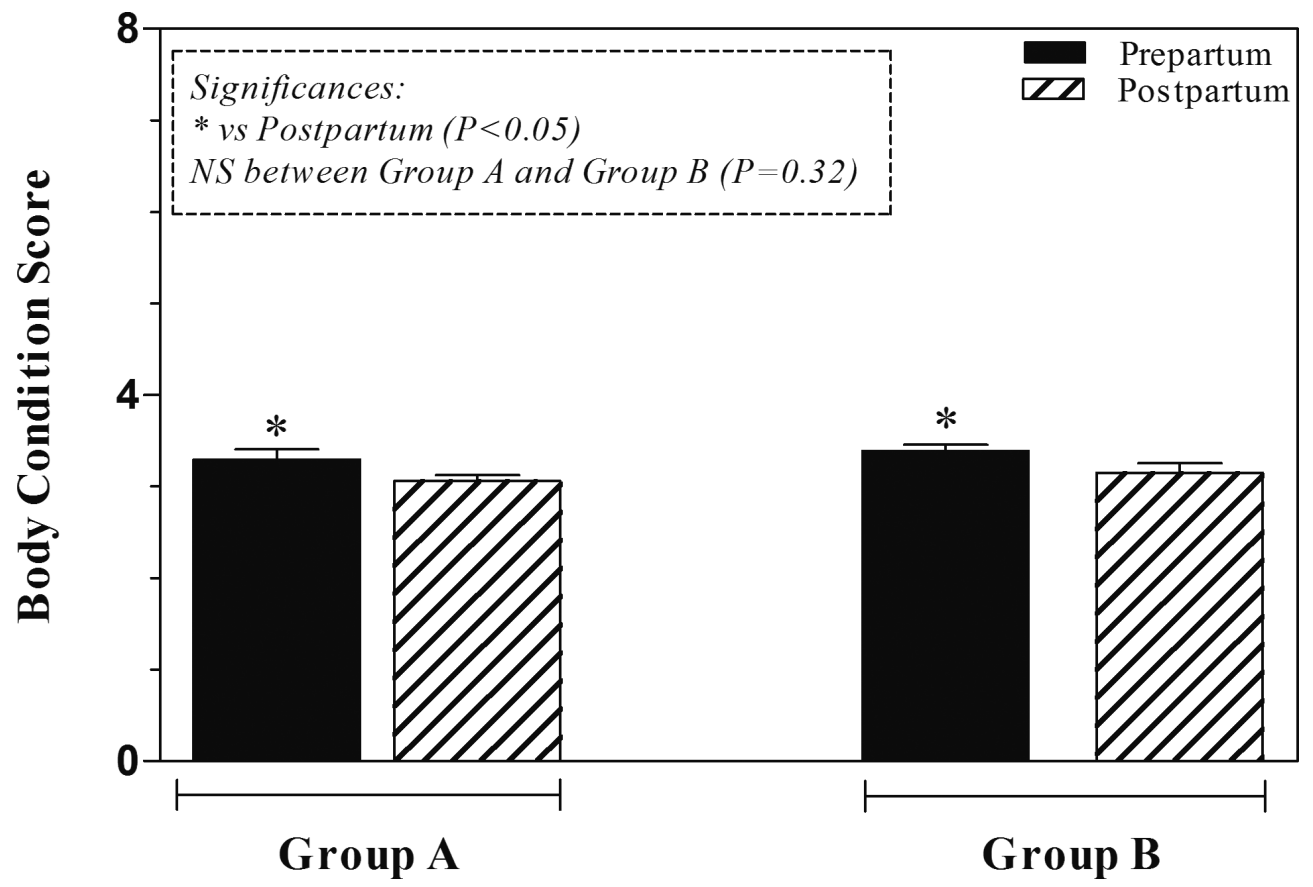

Figure 1

Farming condition and transition period effect on BCS

\section{Discussion}

The transition period affects significantly the metabolic profile and this can justifies the variation of studied parameters during the prepartum and postpartum period. Metabolic changes included alterations in the energy balance that lead to increased lipid mobilization with consequent increase of plasma NEFA concentrations (Contreras et al. 2010).

In the present study, glucose, insulin, BHB and NEFA were significantly affected by the physiological periods considered (prepartum and postpartum) and by GTT both in Group A and Group B. In both groups all parameters showed the same trend in pre- and postpartum period after glucose infusion. Glucose and insulin values were higher in the prepartum period respect to postpartum period before glucose infusion (T0) and for all different timing following 
Group A
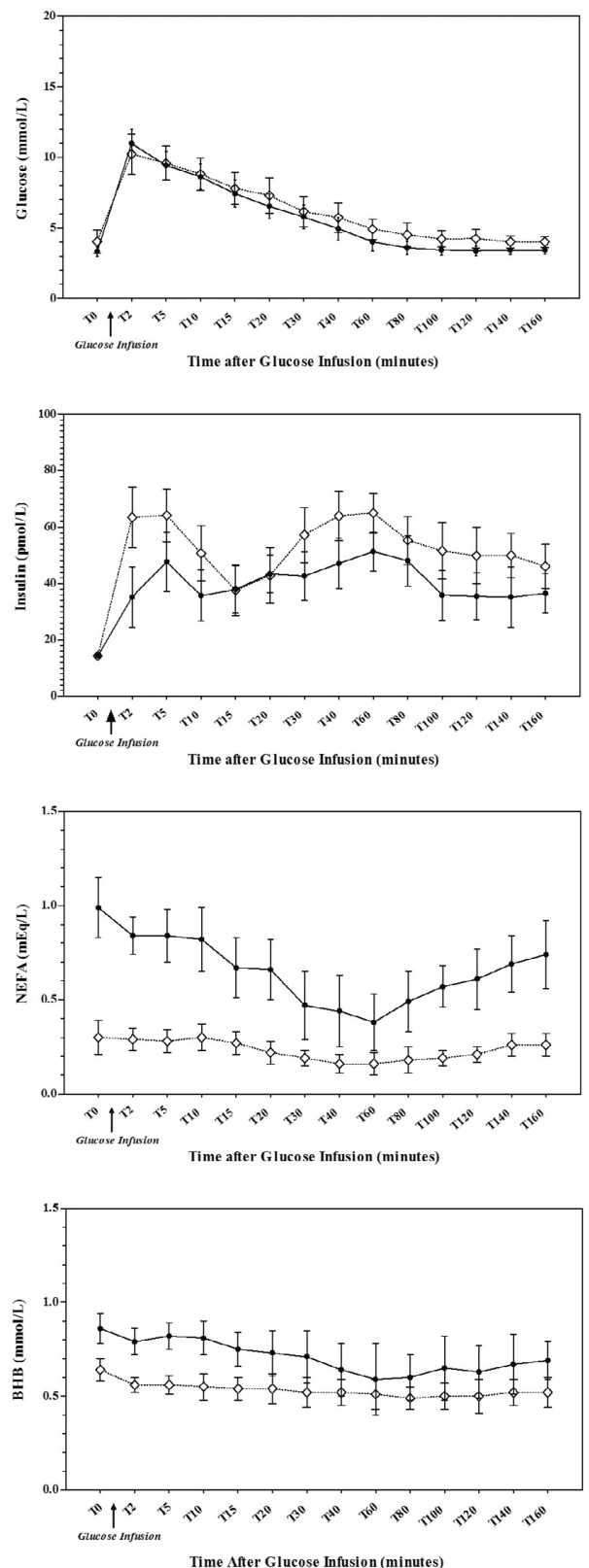

Significant effect of glucose infusion $(P<0.001)$ Significant effect of transition period $(P<0.001)$ NS between Group $A$ and Group $B(P>0.05)$
Group B
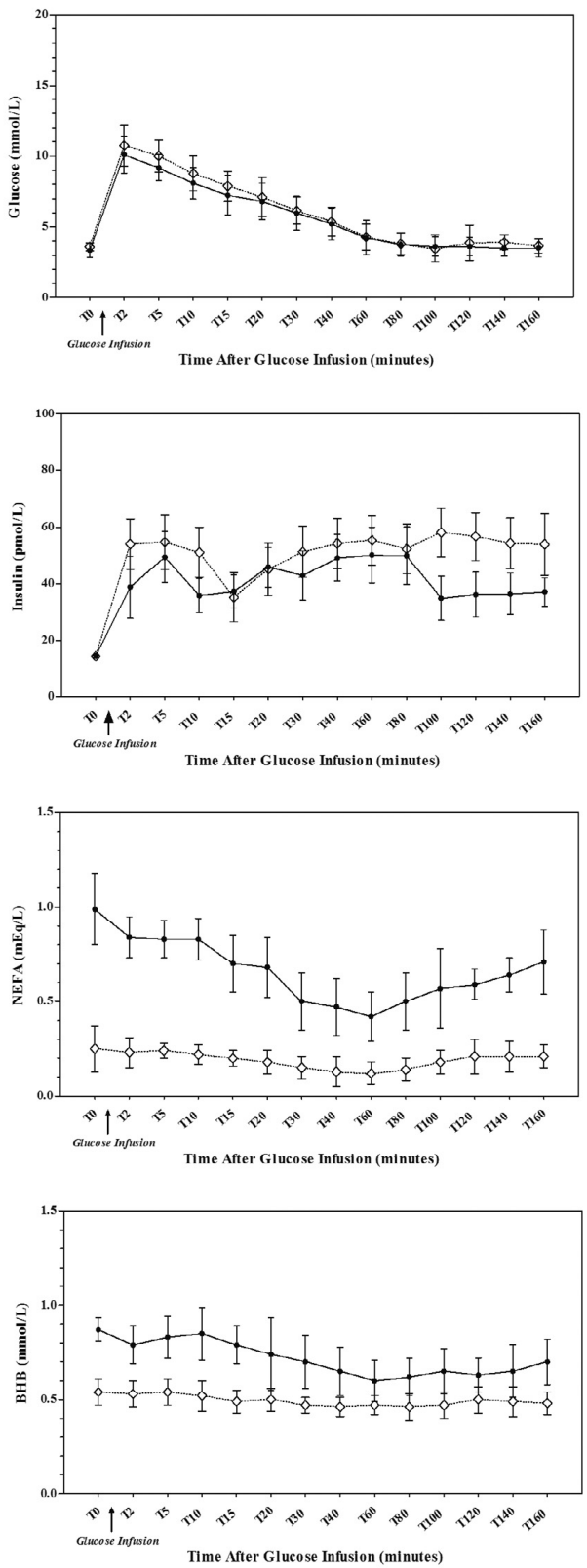

$\diamond \quad$ Prepartum

$\rightarrow$ Postpartum

Figure 2

Trend of glucose, insulin, NEFA and BHB before (T0) and after glucose infusion of Group A and Group B during prepartum and postpartum period 
glucose infusion in both groups. The rate of glucose and insulin during GTT showed a rapid increase two minutes after glucose infusion and a progressive decline to starting values after $160 \mathrm{~min}$ (T160) in both periods. Glucose and insulin trends obtained from this study reflected the metabolic adaptation to postpartum phase, according to previous results (Drackley 1999, Zhao \& Keating 2007). During this physiologic phase insulin resistance inhibits glucose use in insulin-dependent tissue, such as muscle and adipose tissues: glucose can be deviated mainly to non-insulin dependent tissues such as the mammary gland for milk production (Kerestes et al. 2009, Contreras \& Sardillo 2011). Lower glucose and insulin levels found during postpartum period respect to prepartum period, before and after glucose infusion, may be due to a decreased responsiveness of pancreatic $\beta$-cells to a state of hyperglycemia, caused by factors which inhibit the release of insulin, such as the increase of NEFA.

NEFA values showed an opposite trend respect to glucose and insulin. NEFA levels were higher in postpartum respect to prepartum before glucose infusion (T0) and for all different timing following glucose infusion in both groups. These results indicated the activation of lipid mobilization that represented another metabolic mechanism of adaptation to postpartum period (Piccione et al. 2012). In fact, it is well known that low insulin concentration and reduced insulin sensitivity of the tissues around parturition increase lipid mobilization and induces further rises in plasma NEFA concentrations (Hayirli 2006). The use of fat reserves and the activation of lipid mobilization during postpartum period were demonstrated by the lower BCS found in this period respect to prepartum. About response to GTT, NEFA values showed a decrease until 60 min after glucose infusion (T60) and a subsequent increase with return to starting values at T160 both in prepartum and in postpartum period. The early decrease of NEFA values after the glucose administration demonstrates that lipid mobilization of fatty acids is reduced in positive energetic balance condition. The plasma BHB profile followed the same pattern of NEFA concentration.

According to Grummer et al. 2004, the increase of plasma NEFA concentration led to the increase of ketogenesis by hepatocytes. BHB levels were higher in postpartum respect to prepartum before glucose infusion (T0) and for all different timing following glucose infusion in both groups. BHB concentrations recorded at $\mathrm{TO}$ and for all different timing following glucose infusion in prepartum and postpartum both in Group A and in Group B were within the reference range $(0.00-0.86 \mathrm{mmol} / \mathrm{l}$, Radostits et $\mathrm{al} .2007)$ and not execeeded the $1.00 \mathrm{mmol} / \mathrm{L}$. These values indicated no subclinical ketosis (Geishauser et al. 2000). Moreover, the early decrease of BHB levels in response to GTT, demonstrate that, following glucose infusion, the production of ketone bodies was reduced.

The results of this study demonstrated that glucose infusion influenced metabolism in ruminants modifying glucose, insulin, NEFA and BHB profile. These variations indicated that glucose is an important direct controller of metabolic interactions and responses in dairy cow during transition period. The decrease of glucose and the increase of NEFA and BHB found in our study, showed the difficulty of dairy cows to cope with the energy demand characterizing the transition period. These data suggest that reference ranges for diagnostic interpretation of blood metabolite concentrations should be adjusted to time periods relative to calving. Interactions between time period and health status suggest prepartum blood metabolite concentrations may provide some indication to postpartum disease risk and can be useful as a herd monitoring tool. 


\section{References}

Aldoretta PW, Hay Jr WW (1999) Effect of glucose supply on ovine uteroplacental glucose metabolism. Am J Physiol Regul Integr Comp Physiol 277, R947-R958

Allen MS, Bradford BJ, Harvatine KJ (2005) The cow as a model to study food intake regulation. Annu Rev Nutr 25, 523-547

Bell AW, Bauman DE (1997) Adaptations of Glucose Metabolism During Pregnancy and Lactation. J Mammary Gland Biol Neoplasia 2, 265-278

Contreras GA, O'Boyle NJ, Herdt TH, Sordillo LM (2010) Lipomobilization in periparturient dairy cows influences the composition of plasma nonesterified fatty acids and leukocyte phospholipid fatty acids. J Dairy Sci 93, 2508-2516

Contreras GA, Sordillo LM (2011) Lipid mobilization and inflammatory responses during the transition period of dairy cows. Comp Immunol Microbiol Infect Dis 34, 281-289

Drackley JK (1999) Biology of Dairy Cows During the Transition Period: the Final Frontier? J Dairy Sci 82, 22592273

Geishauser T, Leslie K, Tenhag J, Bashiri A (2000) Evaluation of Eight Cow-Side Ketone Tests in Milk for Detection of Subclinical Ketosis in Dairy Cows. J Dairy Sci 83, 296-299

Gillund P, Reksen O, Gröhn YT, Karlberg K (2001) Body Condition Related to Ketosis and Reproductive Performance in Norwegian Dairy Cows. J Dairy Sci 84, 1390-1396

Goff JP, Horst RL (1997) Physiological Changes at Parturition and Their Relationship to Metabolic Disorders. J Dairy Sci 80, 1260-1268

Grummer RR, Mashek DG, Hayirli A (2004) Dry matter intake and energy balance in the transition period. Vet Clin North Am Food Anim Pract 20, 447-470

Guesnet PM, Massoud MJ, Demarne Y (1991) Regulation of adipose tissue metabolism during pregnancy and lactation in the ewe: the role of insulin. J Anim Sci 69, 2057-2065

Hayirli A (2006) The Role of Exogenous Insulin in the Complex of Hepatic Lipidosis and Ketosis Associated with Insulin Resistance Phenomenon in Postpartum Dairy Cattle. Vet Res Commun 30, 749-774

Herdt TH, Emery RS (1992) Therapy of diseases of ruminant intermediary metabolism. Vet Clin North Am Food Anim Pract 8, 91-106

Itoh N, Koiwa M, Hatsugaya A, Yokota H, Taniyama H, Okada H, Kudo K (1998) Comparative Analysis of Blood Chemical Values in Primary Ketosis and Abomasal Displacement in Cows. J Vet Med A 45, 293-298

Kerestes M, Faigl V, Kulcsár M, Balogh O, Földi J, Fébel H, Chilliard Y, Huszenicza G (2009) Periparturient insulin secretion and whole-body insulin responsiveness in dairy cows showing various forms of ketone pattern with or without puerperal metritis. Domest Anim Endocrinol 37, 250-261

Leroy JLMR, Vanholder T, Van Knegsel ATM, Garcia-Ispierto I, Bols PEJ (2008) Nutrient Prioritization in Dairy Cows Early Postpartum: Mismatch Between Metabolism and Fertility? Reprod Domest Anim 43 (Suppl.), 96-103

Morgante M, Gianesella M, Casella S, Stelletta C, Cannizzo C, Giudice E, Piccione G (2012) Response to glucose infusion in pregnant and nonpregnant ewes: changes in plasma glucose and insulin concentrations. Comp Clin Pathol 21, 961-965

Nielsen NI, Ingvartsen KL (2004) Propylene glycol for dairy cows: A review of the metabolism of propylene glycol and its effects on physiological parameters, feed intake, milk production and risk of ketosis. Anim Feed Sci Technol 115, 191-213

Piccione G, Messina V, Marafioti S, Casella S, Giannetto C, Fazio F (2012) Changes of some haematochemical parameters in dairy cows during late gestation, post partum, lactation and dry periods. Vet Med Zoot 58, 59-64

Radostits OM, Gay CC, Hinchcliff KW, Constable PD (2007) Veterinary Medicine: A textbook of the diseases of cattle, horses, sheep, pigs, and goats. 10th ed., Elsevier Saunders, Edinburgh et al., 1661-1667 
Sakha M, Ameri M, Rohbakhsh A (2006) Changes in blood $\beta$-hydroxybutyrate and glucose concentrations during dry and lactation periods in Iranian Holstein cows. Comp Clin Pathol 15, 221-226

Sasaki S (2002) Mechanism of insulin action on glucose metabolism in ruminants. Anim Sci J 73, 423-433

Wathes DC, Cheng Z, Chowdhury W, Fenwick MA, Fitzpatrick R, Morris DG, Patton J, Murphy JJ (2009) Negative energy balance alters global gene expression and immune responses in the uterus of postpartum dairy cows. Physiol Genomics 39, 1-13

Zhao FQ, Keating AF (2007) Expression and Regulation of Glucose Transporters in the Bovine Mammary Gland. J Dairy Sci 90 (Suppl.), E76-E86 